\title{
IMPLICAÇÕES DO USO DE ÁLCOOL NO EXERCÍCIO DAS FUNÇÕES PARENTAIS NA PERSPECTIVA DO FILHO ADOLESCENTE
}

\section{IMPLICATIONS OF ALCOHOL USE IN THE EXERCISE OF PARENTAL FUNCTIONS IN THE PERSPECTIVE OF THE ADOLESCENT CHILD}

\author{
Flávia Michelle Pereira Albuquerque, ${ }^{1}$ Vivian Steffen Heimerdinger, ${ }^{1}$ Edenilson Freitas Rodrigues ${ }^{2}$ \\ ${ }^{1}$ Universidade Regional do Noroeste do Estado do Rio Grande do Sul e Fumssar - Fundação Municipal de Saúde de Santa Rosa/ \\ /Santa Rosa/Brasil. ${ }^{2}$ Universidade Regional do Noroeste do Estado do Rio Grande do Sul e Fumssar - Fundação Municipal de Saúde \\ de Santa Rosa/Santa Rosa/Brasil. Estratégia Saúde da Família Garibaldi Carrera Machado/Santo Ângelo/Brasil.
}

Autor correspondente: Flávia Michelle Pereira Albuquerque $\quad$ e-mail: flaviampa@msn.com

\section{EDITORES}

Thiago Gomes Heck

(Unijuí-Brasil)

Adriane Cristina Bernat Kolankiewicz

(Unijuí-Brasil)

\section{EDITORES DE ÁREA}

Educação \& Saúde

Eva Teresinha de Oliveira Boff

(Unijuí-Brasil)

Fisioterapia \& Saúde

Eliane Roseli Winkelmann

(Unijuí-Brasil)

Ciências Farmacêuticas \& Saúde

Marilei Uecker Pletsch

(Unijuí-Brasil)

Nutrição \& Saúde

Lígia Beatriz Bento Franz

(Unijuí-Brasil)

Nadia Oliveira

(Unipampa-Brasil)

Ingrid Perry

(UNESC-Brasil)

Enfermagem e suas contribuições para a prática

Adriane Cristina Kolankiewicz

(Unijuí-Brasil)

Crhis de Brum

(UFFS-Brasil)

Neila de Souza

(UFSM-Brasil)

\section{Exercício Físico \& Saúde}

Thiago Gomes Heck

(Unijuí-Brasil)

Anderson Zampier Ulbrich

Editora Unijuí

Universidade Regional do Noroeste do

Estado do Rio Grande do Sul (Unijuí)

\section{RESUMO}

O abuso de álcool é um problema de saúde pública considerado pela área da Psicologia um sintoma social. Compreender como se estabelece a função parental para filhos adolescentes de cuidadores alcoolistas foi o objetivo desta pesquisa. Para tanto, foram entrevistados 16 adolescentes cujos responsáveis estavam cadastrados no serviço municipal de referência ao álcool e drogas. Utilizou-se uma entrevista semiestruturada realizada na residência dos jovens. A partir da análise dos dados organizou-se a discussão em três dimensões: representação mental sobre alcoolismo, percepção sobre alcoolismo parental e impacto do alcoolismo na relação parental. Destas dimensões surgiram categorias de ordenamento do discurso dos sujeitos. Percebe-se que os adolescentes podem lidar com o alcoolismo parental como uma conduta normal ou patológica, dependendo principalmente do acesso à informação e da influência do meio em que estão inseridos. Os adolescentes estabelecem uma relação conflituosa com o familiar alcoolista ao perceberem este como instável, alguém que incomoda ou que pode ser tratado com indiferença porque não se pode contar. Conclui-se que nas famílias estudadas, nas quais há o abuso de álcool, a base é frágil e metaforicamente não há construção sólida para a formação da identidade do adolescente. Assim, devido à falta de referência esses jovens vivenciam com sofrimento psíquico maior a crise da adolescência. Ligado a este fato também percebeu-se um discurso do jovem sem perspectivas aprendido na convivência familiar na qual há o abuso de álcool.

Palavras-chave: Relações familiares. Adolescência. Alcoolismo.

Submetido em: 19/2/2016

Aceito em: 2/8/2016 


\section{Revista}

\section{Contexto}

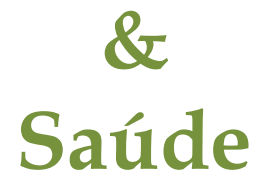

Volume 16

Número 31

2016

ISSN 2176-7114
A Revista Contexto \& Saúde é um periódico do Departamento de Ciências da Vida da Universidade Regional do Noroeste do Estado do Rio Grande do Sul (Unijuí). É um periódico semestral que tem por objetivo a divulgação da produção técnico-científica de temas relacionados à área de Ciências da Saúde.

O escopo da revista abrange a divulgação de resultados de pesquisa que contemplem avanços no processo saúde-doençacuidado e no conhecimento e aplicabilidade de novos processos químicos e biológicos em saúde.

Neste periódico, entende-se que a publicação de estudos com os aspectos epidemiológicos, assistenciais e educacionais em saúde, experimentais e aplicados é uma forma a subsidiar e qualificar a atenção à saúde de modo interdisciplinar.

\begin{abstract}
Alcohol abuse is a public health problem considered by psychology as a social symptom. Understanding how to establish the parental function for adolescent children of alcoholic caregivers was the objective of this research. For this, were interviewed sixteen adolescents whose leaders were registered in the municipal service of reference to alcohol and drugs. A semi-structured interview was conducted in the youth residence. From the data analysis, the discussion was organized in three dimensions: mental representation about alcoholism, perception about parental alcoholism and impact of alcoholism on the parental relationship. From these dimensions emerged categories of ordering of subjects' discourse. It is noticed that adolescents can deal with parental alcoholism as a normal or pathological behavior, depending mainly on access to information and the influence of the environment where they are inserted. The adolescents establish a conflictual relationship with the familiar alcoholic when they perceive this as unstable, someone who bothers or can be treated with indifference because it can not be counted. It is concluded that in the families studied, in which there is alcohol abuse, the basis is fragile and metaphorically there is no solid construction for the formation of the adolescent's identity. Therefore, due to lack of reference these young people experience with greater psychic suffering the crisis of adolescence. Tied to this fact, we also noticed a discourse of the young person with no perspectives learned in the familiar coexistence in which there is the abuse of alcohol.
\end{abstract}

Keywords: Family relationships. Adolescence. Alcoholism. 


\section{INTRODUÇÃO}

De acordo com Silva (2003), a relação do homem com o álcool é tão antiga quanto o mundo, podendo até mesmo ser considerada normal ou funcional, desde que a satisfação decorrente do uso desta substância superasse os prejuízos que ela pode provocar aos usuários e não lhes subtraísse a liberdade de decidir quando e como beber. Segundo a autora, entretanto, quando o conjunto de danos provocados pela ingestão de álcool descontrolada começa a afetar, de forma negativa, as pessoas e a coletividade, esta relação passa a ser chamada de alcoolismo e, a partir de então, transforma-se num dos maiores flagelos do mundo atual.

Melman (1992, p. 9) explicita:

Pode-se falar de sintoma social a partir do momento em que a toxicomania é, de certo modo, inscrita, mesmo que seja nas entrelinhas, no discurso que é o discurso dominante de uma sociedade em uma época dada.

O desenvolvimento de uma toxicomania se dá pelo encontro de um produto e de um indivíduo, ou seja, precisase de pelo menos dois elementos de causalidade, um de ordem intrapsíquica e outro biológico, e ainda não devendo se descartar os fatores do meio sociocultural dos sujeitos (OLIVENSTEIN, 1985). Assim sendo, são necessários três parâmetros: o encontro de um produto, de uma personalidade e de um momento sociocultural.

A toxicomania, para Gervais apud Baumkarten (2006), é uma conduta aditiva definida como a relação acentuada e passional de um indivíduo em relação a um objeto de dependência. E Miguel (apud BAUMKARTEN, 2006) descreve a toxicodependência como uma epidemia social, mas, ao contrário das demais epidemias, nesta o sujeito se disponibiliza voluntariamente, ou seja, as vítimas se oferecem ao sacrifício.

Os toxicômanos têm um sentimento de que podem a qualquer momento recomeçar, e este risco e jogo com a morte é assumido e procurado (BAUMKARTEN, 2006). Segundo Garcia (apud BAUMKARTEN, 2006), o consumo abusivo de drogas é um aspecto de nossa sociedade, uma saída encontrada para a tristeza e para os sentimentos de perda que toda a sociedade vive, na qual o luto fica suspenso, mascarado, anestesiado pelo consumo abusivo de drogas. Ramirez (1995) entende a dinâmica da compulsão aditiva como a pretensão em se encontrar um objeto, consumo ou rotina de segurança e calor que não se encontrou na vida interpessoal.

De acordo com Roussaux (apud BAUMKARTEN, 2006, p. 54):

A toxicomania representa um processo secundário, uma organização relacional, até um sintoma como compromisso; parece, entretanto, que seja, sob diferentes formas, o sintoma de toda família, uma espécie de estratégia habitual e consagrada, de via preferencial, para a resolução dos conflitos.

A adolescência pode ser definida como um período entre a infância e a maturidade física, psíquica e social que caracteriza o status adulto, que tem seu início por uma profunda transformação biológica: a puberdade (BAUMKARTEN, 2006). Segundo Rassial (1999), após o estádio do espelho, a adolescência é o momento em que, sob o olhar do outro, o sujeito reapropria-se de uma imagem corporal transformada. Para este autor a adolescência é a fase em que o sujeito responde ao reencontro com a sexualidade não como um adulto, mas com seus próprios meios, os de alguém que organiza seu novo lugar. 
Característica marcante ligada à adolescência é a noção de crise, que segundo Gervais (apud BAUMKARTEN, 2006), é um período de revolta, de oposição e de colocar em causa valores parentais, escolares e institucionais, sendo esta crise salutar e necessária. O conflito básico da crise adolescente é a elaboração do vínculo simbiótico, no qual os processos de desprendimento e diferenciação desorganizam e desestruturam a identidade lograda até este momento. Desta forma, a cultura internalizada, mediatizada e instrumentada pela família prefigura a crise da adolescência ao estabelecer expectativas e exigências de independência, liberdade e competência ao manejo social, situação esta nova e muito diferente do que o sujeito vivia na etapa anterior, de proteção, contenção e limitação que vive o latente (ABERASTURY, 1980).

A primeira e essencial função psíquica da família, portanto, é ofertar afeto, que é fundamental à sobrevivência emocional, além de transmitir as experiências individuais e grupais acumuladas, na medida em que os pais colaboram com a formação da identidade pessoal de seus filhos (SOUZA; BAPTISTA, 2008). Segundo o mesmo autor, entende-se como suporte familiar o cumprimento de determinadas funções da família, tais como: coletar e disseminar informações sobre o mundo, transmitir ideologias, ajudar na formação de identidades, oferecer serviços práticos de ajuda concreta, apoio emocional, orientação e feedback e ainda guiar e mediar na solução de problemas, servindo de refúgio para repouso e recuperação de seus membros.

Sendo a adolescência caracterizada por momentos de particular complexidade, que deixam marcas provenientes dos registros vivenciais, deve-se pensar que os relacionamentos estabelecidos nesse período da vida serão determinantes para a formação de laços e redes do jovem.

Uma relação parental que já se constituiu na fragilidade e ausência de vínculos é colocada novamente em foco com a entrada dos filhos na adolescência. Isso porque nessa fase ocorrem mudanças físicas em consequência da puberdade, cognitivas com o surgimento de habilidades mais aprimoradas e relativas ao desenvolvimento social em decorrência da desvinculação emocional dos pais e aproximação com o grupo de pares (CASTRO; STURMER; ALBORNOZ, 2009). Segundo a autora, sabe-se que o relacionamento com os pais segue sendo importante como fonte de segurança e referência, ainda que o luto pelos pais da infância aconteça por haver uma decepção em função da percepção de seus defeitos. O efeito é uma imagem mais realista e menos idealizada desses pais, facilitando assim o desligamento deles.

Conforme Silva (2012), o uso de álcool é apontado como um fator gerador de conflitos no meio familiar, podendo refletir-se em consequências traumáticas para o desenvolvimento dos filhos do alcoolista, tais como: baixo desempenho escolar, comportamentos agressivos, baixa autoestima, isolamento social, ansiedade, entre outras. As consequências do alcoolismo parental variam de acordo com características pessoais de cada filho, a idade em que vivenciaram as consequências da dependência química, a rede de apoio que o circunda e o grau de violência familiar (SOUZA, 2008). A família pode ser vista como a principal fonte de suporte, mas também de estresse para seus membros, afetando de maneira poderosa nos processos de saúde e doença (SOUZA; BAPTISTA, 2008).

Segundo Souza e Carvalho (apud SILVA, 2011), o alcoolismo parental distorce os processos e os papéis familiares, e nessa tentativa do filho de lidar com a desorganização e inconsistência emocional do ambiente familiar, ele pode assumir três papéis: responsável, ajustador e conciliador. Sabe-se que cada papel geralmente identifica um padrão de comportamento de super ou sub-responsabilidade, podendo ainda assumir uma multiplicidade de papéis nessas famílias de alcoolistas, como: substituto parental para os irmãos e irmãs mais novos ou substituto marital com o genitor não alcoolista (SILVA, 2011).

A representação mental que os adolescentes podem ter a respeito do uso de álcool pode ser observada segundo duas perspectivas: a primeira, em que os adolescentes acham "natural", pois o uso de álcool é entendido com 
naturalidade e como parte do meio em que estão inseridos. A segunda, entendida como "patológica", indo ao encontro do que é preconizado pelo Ministério da Saúde que relata que o uso de álcool impõe às sociedades agravos indesejáveis e dispendiosos que acometem os indivíduos em todas as esferas de sua vida.

Quanto às percepções sobre o alcoolismo parental, pode-se pensar que emergem imagens e sentimentos sobre o familiar alcoolista, como a "dicotomia", na qual o jovem se alterna entre o pai bom e o pai mau, que por vezes assume o papel de proximidade e cuidado, de referência e afeto, e em outros momentos assume uma posição de esquiva e rechaço. A "sobrecarga", pois o pai não ocupa um lugar de reconhecimento, sendo visto pelo adolescente como privado de reconhecimento social e poder decisório. Outra percepção é a de "desajuste" vinculada a uma relação fragilizada em virtude dos conflitos inerentes nessas relações nas quais permeia o abuso de álcool. Além disso, a "indiferença" quando os adolescentes relatam que o abuso de álcool por parte dos cuidadores não interfere em nada nas relações familiares, podendo-se refletir sobre a banalização do alcoolismo em nossa sociedade.

O impacto do alcoolismo na relação parental é observado a partir de três momentos da vida dos adolescentes: o passado, o presente e o futuro. No "passado" aparecem as más lembranças relacionadas ao uso de álcool e boas lembranças que não envolvem o familiar alcoolista. No "presente" ficam evidentes as preocupações e atitudes de afastamento dos adolescentes quanto ao familiar abusador de álcool, mas também a esperança de que o familiar alcoolista escolha a melhora ou o tratamento, ainda que reiteradamente não obtenha sucesso. E no "futuro" emergem as expectativas de não abuso de álcool por parte do familiar e assim podendo se manter a proximidade com ele, mas também o distanciamento como única possibilidade de um futuro melhor para o adolescente.

Trabalhando em Unidades Básicas de Saúde (UBSs), surge a preocupação quanto à qualidade do suporte familiar oferecido a estes adolescentes filhos de pai e/ou mãe alcoolista, visto que em todas as UBSs do município são realizados atendimentos a usuários de álcool e seus familiares. Este tema faz parte da rotina das UBSs, mas não se tem estudos sobre a repercussão na vida do adolescente e apontamentos do que podemos oferecer para esses jovens como recursos e apoio.

Articulando a função de suporte familiar às demandas da adolescência e acrescentando-se a este cenário o sintoma social do alcoolismo, o objetivo desta pesquisa foi identificar como se estabelece a função parental para adolescentes cujo cuidador é dependente de álcool. Além disso, investigaram-se quais as percepções desses adolescentes sobre seus cuidadores abusadores de álcool, bem como a postura e o discurso do adolescente diante do alcoolismo parental, pois, conforme Balzac (apud OUTEIRAL, 2008, p. 13):

Na vida íntima das famílias chega um momento em que, voluntária ou involuntariamente, os filhos passam a ser juízes de seus pais.

\section{DELINEAMENTO METODOLÓGICO:}

Foram entrevistados 16 adolescentes entre 12 e 18 anos de idade incompletos, filhos de pais/mães/responsáveis alcoolistas. A idade escolhida deu-se em virtude do que delimita o Estatuto da Criança e do Adolescente (ECA), que diz em seu artigo $2^{\circ}$ que adolescente é aquele que tem entre 12 e 18 anos de idade.

Assim determinaram-se como critérios de inclusão na pesquisa o fato de estar dentro da faixa etária citada, residir no município no qual a pesquisa foi realizada e ter um responsável cadastrado no CAPS AD (Centro de 
Atendimento Psicossocial - Álcool e Drogas), este o serviço de referência do sistema municipal de saúde no acompanhamento dos casos de dependência química.

Os pesquisadores realizaram visitas domiciliares aos adolescentes e familiares. Num primeiro momento conversaram com ao menos um responsável pelo adolescente explicando os objetivos da pesquisa, os riscos e benefícios e, assim, este responsável foi convidado a assinar o Termo de Consentimento Livre e Esclarecido (TCLE) autorizando o adolescente a participar da pesquisa. Num segundo momento foi conversado da mesma maneira com o adolescente que foi convidado a participar da pesquisa e assinar o Termo de Assentimento para atender à Resolução no 466, de 12 de dezembro de 2012, do Conselho Nacional de Saúde.

Foi elaborado um questionário semiestruturado com o objetivo de conhecer como se estabelece a função parental para filhos adolescentes de cuidador alcoolista. A pesquisa foi realizada a partir de uma investigação analítica e descritiva com abordagem qualitativa e para análise dos dados utilizou-se a técnica de Análise de Conteúdo, que permitiu compreender criticamente o sentido das falas e descobrir elementos ocultos, indo além das aparências do que estava sendo comunicado, sempre levando em consideração as respostas expressas nos questionários.

Segundo Caregnato e Multi (2006, p. 4):

A maioria dos autores refere-se à análise de conteúdo como sendo uma técnica de pesquisa que trabalha com a palavra, permitindo de forma prática e objetiva produzir inferências do conteúdo da comunicação de um texto replicáveis ao seu contexto social. $\mathrm{Na}$ análise de conteúdo o texto é um meio de expressão do sujeito, onde o analista busca categorizar as unidades de texto (palavras ou frases) que se repetem, inferindo uma expressão que as representem.

Mozzato e Grzybovski (2011) relata que a análise de conteúdo é um conjunto de técnicas de análise de comunicações, que tem como objetivo ultrapassar as incertezas e enriquecer a leitura dos dados coletados, tendo como objetivo compreender o sentido das comunicações, seu conteúdo manifesto ou latente e as significações explícitas ou ocultas. E de acordo com Gallert et al. (2015), cada vez mais pertinente e necessária à compreensão da realidade, aqui entendida pelo viés da perspectiva histórica, a subjetividade vem ocupando lugar na reflexão da ciência como processo de construção do conhecimento. Observam ainda que o debate atual indica que o conhecimento sobre o sujeito não pode prescindir do olhar atento sobre as tramas que o envolvem, sobre as formas como ele se expressa e se articula com o mundo a sua volta e sobre a complexidade de sua configuração individual.

Este estudo foi aprovado pela Comissão Científica do Núcleo de Ensino e Pesquisa (NEP) da Fundação Municipal de Saúde de Santa Rosa/RS (Fumssar) e pelo Comitê de Ética em Pesquisa sob parecer $n^{\circ} 1.162 .441$, em 27 de julho de 2015, atendendo à Resolução no 466/2012 e estando de acordo com os padrões éticos exigidos. Além disso, esta pesquisa foi financiada por meio do edital $n^{\circ}$ 01/2015 do Núcleo de Ensino e Pesquisa (NEP) da Fundação Municipal de Saúde de Santa Rosa/RS.

\section{RESULTADOS E DISCUSSÕES:}

“...Há nomes que são destinos., 1

A partir da análise do discurso dos sujeitos adolescentes, iniciou-se esta "trajetória" que trata da discussão das perspectivas à luz do referencial teórico utilizado. Em termos práticos, separou-se este referencial em três 
dimensões de discussão: representação mental do alcoolismo, percepção do alcoolismo parental e impacto do alcoolismo na relação parental. Em cada dimensão recorreu-se à interlocução entre os autores e atores (adolescentes) da pesquisa mediante a organização de categorias que ordenaram os discursos e proporcionaram entendimento adequado ao tema.

\section{Representação Mental Sobre Alcoolismo}

"O álcool é uma mentira que provoca o desejo, mas elimina a performance.",

A respeito da representação mental sobre o uso de álcool, ou melhor, sobre a maneira como tratam/lidam com o uso abusivo de álcool, observou-se a citação de duas categorias:

"Natural": Aparece quando mencionam que conhecem bebida alcoólica, que sabem que os pais e/ou responsáveis fazem uso desse tipo de bebida, além de amigos e vizinhos. Pode-se perceber que a bebida alcoólica é vista com naturalidade e como parte do meio em que estão inseridos, portanto trazem a representação de que se vive atualmente em uma sociedade que tem o alcoolismo como sintoma social e desta forma há uma banalização do alcoolismo nas famílias. "Normal, ele escolhe o que faz né, a mãe não gosta, eles brigam, mas depois já voltam e tá tudo bem" (Gabriel) ${ }^{3}$ e "Eu não sinto nada, já estou acostumado com isso" (Leonardo) $)^{4}$ é o discurso dos participantes que mostra a naturalização do uso de álcool e juntamente com esses discursos Drugg, Freire e Campos (2010) advertem que o alcoolismo é característico das sociedades modernas. Nas sociedades antigas a bebida alcoólica era usada em rituais religiosos, não compondo quadros de dependência, portanto tendo um sentido. Como se fez referência, contudo, em nossa sociedade isto não se faz presente. Além disso, percebe-se que esses jovens assumem um papel de sub-responsabilidade, não se envolvendo nas escolhas familiares e demonstrando que isto não os afeta.

Atualmente a bebida alcoólica também é vista no discurso popular contemporâneo como alusão à comemoração a uma conquista pessoal, com o termo "bebemorar" (DRUGG; FREIRE; CAMPOS, 2010). Também se relaciona o consumo de álcool com experiências constitutivas da subjetividade do sujeito como relativas à sexualidade, ao amor, ao desejo, á culpa, etc., e que não deveriam ser pensadas como negativas, mas em que aparece a ingestão de álcool como solução para suportar tais experiências (DRUGG; FREIRE; CAMPOS, 2010). Como diz Sofia:" "É uma coisa que vicia, que traz felicidade momentânea para a pessoa, ainda que depois vicie" e "Acho normal, trabalham a semana inteira, querem se divertir um pouco, mas não pode ser demais, me sinto normal com isso, só é ruim quando é demais" (Vitor) ${ }^{6}$.

Sabe-se que as drogas sempre existiram e os homens, para atenuar seu sofrimento físico ou psíquico ou para buscar prazer, utilizam-se dessas substâncias que lhe produzem uma falsa sensação de bem-estar (OUTEIRAL, 2008). Ainda segundo este autor, as drogas lícitas (álcool e tabaco) são utilizadas em ampla escala e causam problemas físicos, psíquicos e sociais, porém a sociedade adota uma conduta falsa e hipócrita em relação a elas, permitindo seu uso e tirando aparentes benefícios dele, quando na verdade, gasta-se muito mais com tratamentos das doenças derivadas do uso dessas drogas do que se recolhe em impostos.

O alcoolista é aquele que bem ou mal torna-se adulto, até mesmo um velho antes da hora, tentando sustentar a sociabilidade, mentindo para ser aceito ou rejeitado por seus semelhantes, tentando o diálogo com os outros (RASSIAL, 1999). O que fica silenciado no discurso social é que o uso do álcool responde à lógica de uma sociedade de consumo, tem uma função social de anestesiamento do mal-estar físico e psíquico e cria a ilusão de felicidade, pertencimento e mobilidade social (DRUGG; FREIRE; CAMPOS, 2010) o que se vê expresso na fala de Vitor: "Acho normal, trabalham a semana inteira, querem se divertir um pouco, mas não pode ser demais. Me sinto normal só é ruim quando é demais", criando desta forma uma "falsa felicidade" para estar de 
acordo com o que é imposto pela sociedade atual, que pode ser vista nas propagandas transmitidas nos meios de comunicação que associam o uso de álcool e tabaco com beleza e força, sedução do sexo oposto, sucesso profissional, riqueza, etc. (OUTEIRAL, 2008). E assim, o jovem que está em busca de valores para se constituir como sujeito, acaba sendo presa fácil da mídia e da sociedade e banaliza o uso dessas substâncias, achando "natural" seu consumo abusivo.

"Patológico": Foi constatado ao mencionarem que têm conhecimento do alcoolismo parental e que acreditam que há tratamento desde que o sujeito tenha esse desejo: "A pessoa tem que querer se internar e querer mudar" (Agata) ${ }^{7}$, "Tem que ter vontade de parar" (Nicolas) ${ }^{8}$ e "Tratamento o posto (Unidade Básica de Saúde) dá, mas eu acho que se a pessoa realmente não quiser não tem como parar, tem que ser de dentro da pessoa... tem gente que fica nove meses ou um ano, mas se a pessoa não quiser não vai sair, porque para isso tem que vir uma força interior e o apoio da família também" (Sofia).

O abuso de álcool é situação comum encontrada na Atenção Básica e a abordagem tem como objetivo a detecção precoce de problemas relacionados, além da integração do tratamento de outras patologias agravadas pelo álcool (BRASIL, 2013). O uso de álcool impõe às sociedades de todos os países muitos agravos indesejáveis e dispendiosos que acometem indivíduos em todas as esferas da vida (BRASIL, 2003). O diagnóstico e tratamento precoce da dependência de álcool têm papel fundamental no prognóstico do abusador, o que se amplia em uma perspectiva global de prevenção e promoção de saúde e se agrava ao se verificar o despreparo e desinformação de quem lida diretamente com o problema, sejam os familiares ou profissionais (BRASIL, 2003).

Pensar formas de cuidar as pessoas que contemple intervenções precoces, dentro de uma lógica de redução de danos, geraria um impacto altamente positivo sobre a carga global de problemas e sobre o custo direto e indireto associado ao consumo de álcool (BRASIL, 2003). Desta forma, a Política Nacional de Atenção à Saúde, de forma relacionada ao consumo de álcool, implica a instituição da assistência, ampliando a cobertura e o espectro de atuação do Programa Nacional de Atenção Comunitária Integral a Usuários de Álcool e Outras Drogas, do Ministério da Saúde, o qual contempla a assistência a pessoas com problemas relacionados ao uso de álcool e seus familiares (BRASIL, 2003).

Desta maneira, os jovens têm razão ao elencar o desejo como possibilidade de mudança na condição de alcoolismo, pois o próprio programa previsto pelo Ministério da Saúde considera a necessidade de estruturação e fortalecimento de uma rede de assistência centrada na atenção comunitária associada à rede de serviços de saúde e sociais, que tenha ênfase na reabilitação e reinserção social dos usuários (BRASIL, 2003). É necessário considerar ainda que a atenção psicossocial a sujeitos com dependência e/ou uso prejudicial de álcool e outras drogas deve basear-se em uma rede de dispositivos comunitários, interligados ao meio cultural e articulados à rede assistencial em saúde mental e aos princípios da reforma psiquiátrica.

\section{Percepção Sobre Alcoolismo Parental:}

Ao analisar a percepção quanto ao familiar alcoolista emergiram dos discursos as seguintes categorias:

"Dicotomia": Percebe-se que o adolescente alterna entre o pai que não ingere bebida alcoólica e o que ingere bebida de álcool, assim sendo, o pai bom e o pai mau, que por vezes assume um papel próximo, de referência e afeto, e em outros momentos está numa posição de esquiva e desprezo. Tais:" "Ele é legal, tá sempre com a gente, mas quando bebe é ruim porque ele briga muito. Ele parece que sai de si", assim como Carlos:" "Muito boa mãe, ela é legal, parceira, só quando bebe é ruim. A vó também bebia, mas me criou até os 6 anos aí ela morreu (cirrose crônica). Era muito bom viver com ela, agora estou com a mãe", e Antônio ${ }^{11}$ completa: "Ele é gente boa, mas bebe e fica chato, não dá para querer ficar perto dele, fica mala mesmo". 
Desta forma, os efeitos do alcoolismo no âmbito familiar aparecem como queixas provindas das companheiras sobre a violência que percebem como efeito de o marido estar alcoolizado. A percepção muda e quando ele está sóbrio tudo volta ao "normal", estabelecendo-se desta maneira um circuito do qual a agressão é elemento constituinte (DRUGG; FREIRE; CAMPOS, 2010).

O alcoolismo distingue-se de todas as outras afecções mentais não pelo comportamento que o envolve, mas pelo tipo de discurso que é modulado pela submissão (MELMAN, 1992). Segundo este autor, o humor do alcoolista varia segundo um ciclo rápido que vai da expansão eufórica e megalomaníaca à depressão suicida, que alimentam a culpabilidade e o sentimento de indignidade.

"Sobrecarga": Percebe-se nestas famílias que o pai não ocupa um lugar de reconhecimento, pois é descrito pelos adolescentes como privado do reconhecimento social e do poder de decisão, visto que oscila de humor e é percebido como aquele que "Faz mal para todo mundo" porque consome bebida de álcool, segundo $V_{\text {Valentina }}^{12}$ e sobrecarrega a companheira, segundo Márcio "A mãe, coitada, que tem que aguentar, ela é doente, mas tem que aguentar”, e assim, por vezes, acaba sendo um estranho em seu próprio lar. Em muitas famílias o pai está ausente psicologicamente, levando ao enfraquecimento da imagem do genitor, ligado a uma redistribuição de papéis, dos status e das imagens de homem e de mulher na sociedade, em que se modificam os processos de identificação oferecidos aos jovens. Os pais infantis idealizados também são perdidos e com isso a ideia ilusória de proteção plena, ao mesmo tempo em que os pais não são mais temíveis e poderosos, surgindo assim uma visão dos pais calcada na realidade, possibilitando uma relação mais igualitária, facilitadora de diálogos e questionamentos (MACEDO, 2012). Percebe-se também que esse adolescente assume um papel de conciliador auxiliando na relação parental, ao mesmo tempo em que esse pai já não tem mais seu papel paternal estabelecido, deixando uma lacuna importante na identificação oferecida ao filho.

De acordo com Savietto e Cardoso (2006), o investimento em novos objetos, em modelos divergentes dos parentais, implica o reconhecimento destes como alteridade digna de se desejar. A edificação de novos modelos na adolescência requer que o sujeito possa desprender-se do passado, de seu corpo infantil, dos pais da infância, apostando no futuro, no próprio vir a ser. Nesse contexto, a família é entendida como rede primária de interação social e provedora de apoio indispensável à manutenção da integridade física e psicológica do indivíduo. Desta forma, torna-se referência nas crenças, valores e comportamentos do indivíduo, à medida que pune ou premia suas atitudes, orientando-o quanto à forma de agir (CAMPOS apud SOUZA; BAPTISTA, 2008). O discurso desses adolescentes põe em reflexão como estão sendo esses modelos parentais, uma vez que os responsáveis não são referência para o jovem e além disso, não ocupam lugar de reconhecimento nas famílias.

"Desajuste": Aparece no discurso vinculado ao conflito inerente a uma relação fragilizada, como na fala de Sofia, que diz: "Interfere demais porque vamos supor que você quer pedir uma coisa para ela (mãe) ou que tu quer conversar de uma forma agradável tu não vai conseguir, pois tudo que tu falar pode ofender ela. Ela vai querer conflitar contigo e uma pessoa de personalidade forte não vai ficar quieta, assim cada vez vai gerar mais briga", e outros adolescentes ressaltam: "Quando ele está bebendo briga demais, mas aí no dia seguinte vem e me abraça e pede desculpas" (Jaqueline) ${ }^{14}$ e "Saio de perto porque fica chato" (Tais), e ainda "Não dá vontade de ficar perto" (Agata) e "Começa a 'loquiar', fica bem fora e isso é ruim, não dá para conviver bem" (Valentina). Leonardo finaliza "Sim, porque quando ele (pai) bebe ele me diz coisas que quando está são não fala e isso magoa". Jaqueline em sua fala demonstra que assume um papel de ajustadora, daquela que ameniza os desconfortos familiares, que aceita e tolera os conflitos inerentes ao abuso do álcool. 
"Indiferença": Aparece quando segundo os participantes o fato de o cuidador ser usuário abusivo de álcool não interfere no seu relacionamento com ele, pois segundo Nicolas "Não (interfere), porque as pessoas conversam mais"; Vitor "Tanto faz, ela (relação) é boa”; Carlos "Ela é boa mesmo assim” e Márcio, "Tanto $f a z$ ". O que nos traz novamente a questão da banalização do alcoolismo em nossa sociedade, bem como a submissão aos ciclos de violência impostos pelo álcool. Compreender o alcoolismo como sintoma social é entender que também se naturaliza a falta de imagens de identificação, deixando os adolescentes à deriva, sem continência, suporte de identificação, limites e definições morais. Equivale a um ego desorientado e desamparado.

No rumo deste entendimento, a qualidade do encontro com o semelhante, desde os primeiros anos de vida, foi ressaltada por Freud como sendo ímpar na construção das formas como este sujeito vai se relacionar durante sua vida. Esses registros, portanto, trarão marcas da subjetividade desde o outro que alicerça a necessidade de cuidado que se impõe, constituindo uma modalidade de encontro que denuncia a inegável condição de desamparo inicial da criança (MACEDO, 2012).

Nessa perspectiva, a autora considera a importância das relações que o adolescente teve com seus pais e outras figuras e âmbitos de sua vida, e deve-se ponderar sobre as influências desses encontros e do contexto social em que vive. E nas famílias nas quais temos familiares importantes com figuras de vínculos frágeis, pensa-se que os laços não serão bem estabelecidos e o adolescente trará em seu desenvolvimento marcas desta falta, deste desamparo que poderá repercutir na vida adulta desse sujeito, seja por intermédio de um sujeito com baixa autoestima ou em casos mais graves com transtornos de conduta e delinquência.

Por fim concluiu-se que na adolescência as funções parentais estão marcadas pelo interdito edípico, podendo-se afirmar que a intensidade da presença ou ausência, assim como a qualidade com que exercem suas funções parentais, são de extrema importância para o adolescente (MACEDO, 2012). Seja na indisponibilidade dos pais ou na desautorização das funções parentais, a impossibilidade do reconhecimento das diferenças traz repercussões significativas na forma de os adolescentes se posicionarem diante das exigências de sua vida.

\section{Impacto do Alcoolismo na Relação Parental}

Esta dimensão tornou-se a mais complexa e subjetiva levantada na pesquisa. Ao tentar-se analisar o impacto do uso do álcool nesta relação, elegeu-se três categorias, com cada uma delas composta por subcategorias.

“Passado”: Foram investigadas lembranças de infância, aparecendo as subcategorias:

- “Boas lembranças”: Estas lembranças não foram relacionadas ou não estão ligadas ao familiar abusador de álcool - "Com minha irmã e irmão brincando na casa da vó” (Jaqueline), "Minhas amigas" (Valentina), "Acho que com meus parceiros da rua brincando" (Gabriel), "Brincando com meus irmãos" (Diogo) ${ }^{15}$, "Jogando bola, sou apaixonado por bola" (Carlos), "Quando ia no parque com minha mãe" (Vitor), e Sofia, que relatou "Foi num final de ano que a gente estava distante, todo mundo mesmo, em outra cidade. Meu irmão em uma (cidade), minha irmã em outra (cidade) aí no final de ano que me lembro a gente reuniu os quatro irmãos e os genros e as noras, e minha mãe e meu padrasto. A única coisa de antigamente e uma coisa que não acontece mais".

- "Más lembranças": Estando ligadas ao uso de álcool pelo familiar responsável ou outra pessoa. Ele Amanda 16 relata "Quando meus pais brigam, eles brigam muito", "Meu pai bebendo e minha mãe gritando com ele. às vezes quebrando as coisas de casa" (Gabriel) e "Foi quando a gente foi para N.H. aí teve uma briga lá com meu irmão e meu padrasto por uma questão de álcool também, eu acho que isso desmoralizou a família... era 
para ser uma viagem boa, mas acabou de um jeito ruim" (Sofia). Luiza ${ }^{17}$ destaca "Meu pai puxando minha mãe da cama e batendo nela e depois ela correndo com a gente e ele dando tiro atrás quando a gente morava lá no interior (engasga e para de falar)", e completa "Só tenho lembranças ruins, são quatorze anos com meu pai bebendo".

"Presente": Fica evidente nos discursos que tratam do relacionamento atual com o familiar alcoolista as preocupações e atitudes dos jovens quanto ao abuso de álcool desse cuidador. Assim foram criadas as subcategorias:

- "Preocupação": Alguns adolescentes quando questionados sobre como se sentem quando o familiar cuidador consome bebida de álcool relatam esse sentimento: "Fico nervosa porque minha mãe pede 'vai lá e faz isso que eu não tenho mais força' dai eu pego e vou lá e falo com ele (pai) e brigo com ele, eu converso, só que fico muito nervosa e começo a chorar desesperada, é ruim" (Laura) ${ }^{18}$. Percebe-se que Laura assume papel de conciliadora nessa relação entre os pais, tomando para si funções do adulto, tendo de ser a responsável familiar num momento de sua vida em que precisa ser amparada e ter modelos de identificação. "Nervosa porque sei que vem brigas" (Luiza) e "É ruim porque ele trabalha para fora, fica 20 dias sem vir para casa e quando vem vai no bar e logo já volta bêbado. É ruim porque a mãe não gosta, aí eles brigam. Ele quebrou o vidro da porta brigando com ela" (Valentina). Na fala de Valentina percebe-se a responsabilidade e o papel de conciliadora que a jovem assume, tentando mediar a situação de abuso de álcool do pai junto a mãe que não tolera tal situação.

A fim de reforçar as consequências deste modo de relação Bowlby (2015) relata que existem evidências de que todo ser humano, independentemente da etapa do ciclo de vida em que esteja, desenvolve melhor seus talentos quando se sente seguro de que existem pessoas que virão em sua ajuda caso necessite. Segundo o autor, no funcionamento da personalidade existem dois conjuntos principais de influências, o primeiro referente à presença ou ausência, parcial ou total, de uma figura de confiança e o segundo relacionado à capacidade ou incapacidade relativa de um sujeito para reconhecer quando a pessoa é digna de confiança e está disposta a fornecer uma base e assim será iniciada e mantida uma relação mutuamente gratificante.

Desta forma, percebe-se que o funcionamento da personalidade saudável origina-se da capacidade do sujeito para reconhecer figuras adequadas que estão dispostas e aptas a proporcionar uma base segura, e ao contrário, pode-se ter sujeitos com apego ansioso, exigentes excessivamente, não envolvimento, indiferença e independência desafiadora.

- “Afastamento": Surge quando a relação é marcada por esse ato: "Saio de perto, não acho ambiente agradável, a pessoa fica chata" (Amanda), "Saio para rua para não ver eles (pais) brigando" (Gabriel), "Me afasto porque sei lá, não gosto" (Agata), "Eu acabo indo para casa das minhas amigas para não ver ele assim" (Valentina) e "Eu fico nervosa, antes eu ficava na sala junto, com ele brigando com todo mundo, mas agora vou para o quarto para não ver tudo isso" (Luiza). A proposta é entender, conforme Macedo (2012), que o desamparo pode ser compreendido por dois grandes eixos. O primeiro é inerente à condição humana e, portanto, essencial à estruturação do aparelho psíquico (e instaurador do desejo) e o segundo que estaria no âmago da falha (no sentido de um cuidado precário do outro), deixando esses sujeitos despreparados para encarar os desafios da vida.

Nas relações em que o "afastamento" está presente, pode-se perceber que o adolescente assume papéis de subresponsabilidade, não se envolvendo com as situações de abuso de álcool e afastando-se fisicamente e emocionalmente do familiar alcoolista. 
- "Esperança": Pensa-se que o sujeito dito adolescente precisa se situar novamente diante dos determinantes reais, imaginários e simbólicos que delimitam sua posição em relação a si mesmo e aos outros, isto é, fundamentalmente a relação ao Outro (MACEDO, 2012). Assim, haver possibilidades para esse Outro na ressignificação da relação é positivo para o futuro. Sofia: "É ruim pedir para ela parar (de beber) porque se ela está bebendo é porque ela quer... ela disse que vai parar, eu me sinto feliz porque beber é ruim para a pessoa e para quem está perto também. A mãe disse que vai parar de beber e fumar, e eu fico feliz porque é uma coisa que a gente vinha lutando há anos". O Outro é aquele que por meio do discurso organiza o laço social, que situa o interdito e que delimita o simbólico.

Segundo Macedo (2012, p. 202):

Considerar a adolescência de um ponto de vista psicanalítico - lacaniano - é, sobretudo, referir-se à determinação do sujeito pelo discurso, tomá-lo como efeito de uma determinada relação com o Outro, marcada pelas operações de alienação/separação.

(...)

O sujeito adolescente é, pois, um sujeito em crise; crise das condições de representação que haviam sido constituídas ao longo da infância. É preciso redefinir sua posição reinscrever-se como sujeito de desejo - diante da demanda veiculada pelo Outro.

Dessa forma, se o responsável alcoolista, mesmo que reiteradamente e sem sucesso, escolhe a melhora ou o tratamento, o adolescente encontra um significado nessa relação e inscreve-se num universo adulto com menor desamparo.

Na fala de Sofia percebe-se um papel de responsabilidade, pois a jovem afirma que lutam há anos para a mãe não consumir mais álcool, o que revela um investimento emocional importante da jovem e dos familiares nessa situação.

"Futuro": Essa categoria emerge quando se avalia as expectativas de futuro dos jovens, surgindo duas subcategorias:

- “Com o alcoolista”: Espera-se um futuro com o responsável incluído: "Quem sabe mais feliz... tendo minha própria vida, trabalhando, tendo minhas coisas, pretendo seguir estudando" (Agata), e "Sei lá... imagino a gente morando em outro lugar, aqui todo mundo cuida da vida de todo mundo, sair daqui" (Laura). Assim os jovens dizem: "Melhorar minha vida e que meus pais parem de brigar" (Valentina) e "Que eu tenha mais parceria e que meus pais parem de brigar porque minha mãe coloca ele para fora de casa, depois voltam e brigam de novo" (Gabriel). "Meu pai sem beber álcool seria muito bom, a gente podia ser feliz" (Jaqueline), "Queria que ele ficasse curado" (Diogo) e "Agora a mãe vai parar de beber e fumar e acho que o único desfalque que a gente tinha era isso, lutar contra a bebida da mãe, o meu padrasto também porque se a mãe não bebe ele não bebe, ele não vai por ele. Então eu imagino uma família bem diferente a partir de agora. Vai partir dela, se ela conseguir e a gente vai ajudar bastante" (Sofia).

Os adolescentes que pensam num futuro junto com o familiar alcoolista assumem papéis de ajustadores e responsáveis, pois desejam que os pais fiquem em harmonia e colocam-se na posição de auxiliar no ajuste familiar.

- "Sem o alcoolista": Alguns adolescentes percebem a única possibilidade de um futuro melhor estando afastados do cuidador alcoolista, como consta nas falas de Márcio e Luiza respectivamente: "Morando lá com minha avó porque lá é tranquilo. Não tem meu pai bebendo, nem a mãe coitada sofrendo" e "Imagino a gente 
bem porque a mãe colocou ele (pai alcoolista) para fora de casa faz um mês e estamos bem sem ele. Tudo tranquilo, sem brigas, sem ofensas". Leonardo diz: "Quero estar trabalhando no quartel, quero ver todos unidos e mesmo com o pai longe quero ver todos bem e que as lembranças ruins fiquem no passado, bem lá atrás”.

Nas falas dos adolescentes que pensam em um futuro sem o familiar abusador de álcool percebe-se que assumem papéis de sub-responsabilidade e um afastamento emocional e físico.

Imaginar o futuro abre possibilidade de idealizar, sonhar e planejar. Afastar o familiar alcoolista é caminho prático, mas não garantia de felicidade. Como alerta Bowlby (2015), a manutenção incontestada de um vínculo é experimentada como fonte de segurança e a renovação de um vínculo é percebida como fonte de júbilo. Além disso, a vinculação tem valor de sobrevivência para uma espécie. E assim sonhar, mesmo que de forma idealizada com a restauração do vínculo familiar, parece oferta mais integrativa ao psiquismo do adolescente.

\section{CONSIDERAÇÕES FINAIS:}

"Está naquela idade inquieta e duvidosa, Que não é dia claro e já é o alvorecer; Entreaberto botão, entrefechada rosa." 19

Cada família é única, mas encontra-se inserida numa determinada cultura, época, com seus problemas, estrutura e sintomas. Nela se estabelecem os laços afetivos e sociais, de cuidado e convivência condicionados por esses valores culturais e socioeconômicos. Assim, instaura-se o sujeito.

Todas as emoções, afetos, normas de convivência, regras e ritos que envolvem uma família geram enredos no sistema familiar e assim se constroem as histórias individuais de cada um, que podem se transformar com o tempo, cultura e mudanças sociais. E como detectou-se na pesquisa, as transformações dos sujeitos podem estar marcadas e atravessadas diretamente pelo alcoolismo.

Percebeu-se que em famílias cujos cuidadores são abusadores de álcool, os demais membros acabam por exercer outros papéis que não o seu, por exemplo, de cuidador, de pai e/ou mãe de irmãos menores, etc. $\mathrm{Na}$ adolescência esse fato traz mais conflito, posto que neste momento o sujeito precisa se reconhecer em seu novo papel, mas se ele nem sabe ao certo qual papel assumir, como poderá se estruturar adequadamente como sujeito?

Os sentimentos e comportamentos despertados em cada um desses adolescentes com familiares/cuidadores abusadores de álcool se condicionará conforme sua personalidade, grau de resiliência, valores e sentimentos perante o alcoolismo. Dessa forma, há um ajustamento subjetivo dos fatores internos e externos.

Segundo Silva (2003), ao admitirem a possibilidade de que a pessoa dependente de álcool "alcooliza" o meio social em que está inserida, autoriza-se que a família sinta e sofra com os efeitos de conviver diariamente com o alcoolismo. Desta forma, a família admite esta "alcoolização" do meio e interage com o contexto, nele fazendo suas trocas, crescendo, diminuindo-se e, muitas vezes, envergonhando-se de sua condição. A "alcoolização", como um viés de conduta, é capaz de gerar na família diversos sentimentos, como: ansiedade, vergonha, raiva, etc., que podem por sua vez conduzir à culpa e à negação, levando ao isolamento social, bem como a um ambiente familiar de constantes brigas e ressentimentos. 
Ainda neste contexto faz-se necessário pensar que se tem um adolescente vivendo um momento de reorganização relativa às identificações. Impõe-se a elaboração do luto das figuras parentais da infância, o que é indispensável para a consolidação do processo subjetivante do adolescente, ao mesmo tempo em que também acontece o enfraquecimento narcísico do sujeito. Assim, os objetos originários que ocupavam, até então, um lugar de certeza, idolatria e onipotência, agora precisam ser desinvestidos. Este processo precisa ser seguro e de amparo para o jovem, que deve ter como alicerce as imagens identificatórias familiares. Nestas famílias, a base é frágil e metaforicamente não há construção sólida quando este alicerce não é seguro e de confiança.

Neste nível de raciocínio acredita-se que cuidar das famílias dos abusadores de álcool é cuidá-las considerando sua complexidade histórica. É necessário cuidar não só do abusador de álcool, mas também dos familiares.

Deve-se promover apoio mútuo e compreensão, evitando o isolamento e a lógica da exclusão entre os membros da família. Concluiu-se que é muito importante para a saúde emocional e perspectivas futuras dos adolescentes que têm cuidadores abusadores de álcool receberem algum tipo de suporte, um olhar cuidadoso, uma vez que a família pode deixá-los invisíveis como sujeitos de direitos. Desta forma, foi articulado junto ao CAPS AD, que é o serviço da rede de atendimento aos usuários de álcool e drogas do município, e também serviço de apoio para familiares de usuários do serviço, o acolhimento dessa demanda e acompanhamento dos adolescentes e demais familiares que assim desejarem.

Mostrou-se importante discutir novamente e reforçar os fluxos da Atenção Primária de Saúde (APS) com o CAPS AD (Centro de Atenção Psicossocial - Álcool e Drogas), assim como as ofertas de serviços para familiares de usuários de álcool e drogas e o acesso ao atendimento para filhos de alcoolistas na rede municipal de saúde do município, enquanto estratégias para qualificar o atendimento a esta população vulnerável. E assim, atuarmos mais proximamente desses jovens, orientando-os e acompanhando-os para que tenham possibilidades de entendimento mais adequadas, bem como acompanhamento por profissional da saúde, seja por meio de atendimento clínico individual, em grupo, seja com atividades educativas em escolas, comunidades, etc. Planejar, portanto, intervenções mais assertivas e resolutivas para fins de qualificação da atenção à saúde dos adolescentes no município.

Sabendo da grande relevância do desenvolvimento de protocolos de atuação dos profissionais da saúde à população adolescente, assim como programas de educação em saúde, enfocando medidas preventivas quanto à criação de vínculos saudáveis e saúde para pais e filhos, acredita-se que esta pesquisa vem colaborar de forma significativa com a população deste local.

Sabe-se que o tema não se esgota aqui, pois muito ainda tem-se para caminhar e estudar sobre o assunto e, pensando nisso, acredita-se que investigar a alarmante frequência com que o alcoolismo tende a recorrer nas famílias e que os sujeitos que crescem nesses ambientes têm maior probabilidade de desenvolver outros problemas de ordem emocional, legal, de conduta e de aprendizagem, leva-nos a pensar sobre novas pesquisas sobre o tema.

A gama de desdobramentos originárias do uso abusivo de álcool por parte dos cuidadores e suas repercussões na vida dos filhos, sejam eles crianças, adolescentes ou adultos, faz pensar na importância de se "olhar" para essas famílias. Assim, é necessário pensar em quais cuidados acolhedores e assertivos para essas demandas cada vez mais crescentes e "naturalizadas" - deve-se ofertar, pois as situações vivenciadas no contexto familiar, em todas as suas dimensões e particularidades, reflete positiva ou negativamente na subjetividade do sujeito.

"Que os jovens modifiquem a sociedade e ensinem os adultos a ver o mundo em forma renovada: 
mas aonde existe o desafio de um jovem em crescimento que haja um adulto para encará-lo". ${ }^{20}$

\section{NOTAS}

${ }^{1}$ Bh. Spinoza apud Outeiral, 2008, p. 81. Os nomes dos adolescentes contidos neste artigo são fictícios e foram escolhidos em alusão à força e resiliência que estes jovens devem ter para superar o alcoolismo parental que já na tenra idade os assola.

${ }^{2}$ Shakespeare apud Outeiral, 2008, p. 39.

${ }^{3}$ Nome fictício Gabriel que significa "homem forte de Deus".

${ }^{4}$ Nome fictício Leonardo que significa "valente como um leão".

${ }^{5}$ Nome fictício Sofia que significa "a sábia".

${ }^{6}$ Nome fictício Vitor que significa "vencedor, vitorioso".

${ }^{7}$ Nome fictício Agata que significa "bondosa".

${ }^{8}$ Nome fictício Nicolas que significa "vitorioso".

${ }^{9}$ Nome fictício Tais que significa "a que se admira".

${ }^{10}$ Nome fictício Carlos que significa "homem guerreiro".

${ }^{11}$ Nome fictício Antônio que significa "valioso, de valor inestimável".

12 Nome fictício Valentina que significa "forte, valente".

${ }^{13}$ Nome fictício Márcio que significa "guerreiro".

${ }^{14}$ Nome fictício Jaqueline que significa "aquela que supera, a que vence".

${ }^{15}$ Nome fictício Diogo que significa "o que vence".

${ }^{16}$ Nome fictício Amanda que significa "aquela que deve ser amada, digna de amor".

${ }^{17}$ Nome fictício Luiza que significa "lutadora, combatente gloriosa".

${ }^{18}$ Nome fictício Laura que significa "vitoriosa".

${ }^{19}$ Machado de Assis, 1994, p. 54.

${ }^{20}$ Winnicott apud Outeiral, 2008, p. 63.

\section{REFERÊNCIAS}

ABERASTURY, A. Adolescência. Porto Alegre: Editora Artes Médicas, 1980.

ASSIS, M. Falenas. Menina e moça. Obra Completa. Rio de Janeiro: Nova Aguilar, 1994. Vol. II.

BAUMKARTEN, S. T. Os significados da drogadição na adolescência. Passo Fundo: Ed. Universidade de Passo Fundo, 2006.

BOWLBY, J. Formação e rompimento dos laços afetivos. 5. ed. São Paulo: Martins Fontes, 2015.

BRASIL. Lei $n^{\circ}$ 8.069, de 13 de julho de 1990. Dispõe sobre o estatuto da Criança e do Adolescente e dá outras providências. Brasília: Distrito Federal, 1990.

- Ministério da Saúde. A política do Ministério da Saúde para atenção integral a usuários de álcool e outras drogas. Brasília: Ministério da Saúde, 2003. 60 p.

. Ministério da Saúde. Cadernos de Atenção Básica, n. 34. Brasília: Ministério da Saúde, 2013. 176 p.

CAREgnATO, R. C. A.; MUTTI, R. Pesquisa qualitativa: análise de discurso versus análise de conteúdo. Texto Contexto Enfermagem, Florianópolis, v. 15, n. 4, 679-684, out./dez. 2006.

CASTRO, M. G. K.; STURMER, A.; ALBORNOZ, A. C. G. Crianças e adolescentes em psicoterapia: a abordagem psicanalítica. Porto Alegre: Artmed, 2009.

DRUGG, A. M. S.; FREIRE, K. S.; CAMPOS, I. F. A. Escritos da clínica. Ijuí: Ed. Unijuí, 2010. 
GALLERT, A. Z. et al. (2015). Subjetividade na pesquisa qualitativa: uma aproximação da produção teórica de González Rey. 2015. Disponível em: $<\mathrm{http}: / / \mathrm{www} . \mathrm{maxwell} . v$ rac.pucrio.br/18055/18055.PDFXXvmi=NUUq4A8CvCO0blPftNpJpQiLhbfW02fNxae2LnEh1shcP8skVS4mJm92zoZzrenppCsb18t2CMes UINRBSflfooPOnpgDNH3qbfsjJuWwKpssek57ArmZQdNeD5SrNVT0cmkWShtDIW7Whd4SFrSwFHMjNFMBCHCO4WMxfgBx dJUvWZpDqia70WqODeqfV3510RZg9Bemk9Th9kVBE6IF4atIoUxlx4mZWlf6WttiEnBOJwpnE93IkwqJrp6qusp>. 29 maio 2015.

MACEDO, M. M. K. (Org.). Adolescência e psicanálise: intersecções possíveis. 2. ed. Porto Alegre: EDIPUCRS, 2012.

MELMAN, C. Alcoolismo, delinquência, toxicomania: uma outra forma de gozar. São Paulo: Escuta, 1992.

MOZZATO, A. R.; GRZYBOVSKI, D. Análise de conteúdo como técnica de análise de dados qualitativos no campo da administração: potencial e desafios. Revista de Administração Contemporânea, Curitiba, v. 15, n. 4, 731-747, jul./ago. 2011.

OLIVENSTEIN, C. O destino do toxicômano. São Paulo: Almed, 1985.

OUTEIRAL, J. Adolescer. 3. ed. Rio de Janeiro: Livraria e Editora Revinter, 2008.

RAMIREZ, L. C. R. La droga em el espejo de la cultura. 2. ed. Santa Fé de Bogotá, Colômbia: Guadalupe, 1995.

RASSIAL, J. O adolescente e o psicanalista. Rio de Janeiro: Companhia de Freud, 1999.

SAVIETTO, B. B.; CARDOSO, M. R. Adolescência: ato e atualidade. Revista Mal-Estar e Subjetividade, Fortaleza, v. 6, n. 1, p. 1543, mar. 2006.

SILVA, M. R. S. Família de alcoolista: o retrato que emerge da literatura. Família Saúde e Desenvolvimento, Curitiba, v. 5, n. 1, p. 9 18, jan./abr. 2003.

SILVA, P. A. Produção de saúde em contextos adversos: um estudo das trajetórias de filhos de alcoolistas. Rio Grande. 2011. Dissertação (Mestrado) - Mestrado em Enfermagem, Universidade Federal do Rio Grande, 2011.

SILVA, P. A. et al. Interações protetoras em famílias de alcoolistas: bases para o trabalho de enfermagem. Revista Enfermagem Uerj, Rio de Janeiro, v. 20, n. 2, 191-196, abr./jun. 2012.

SOUZA, J. Filhos de alcoolistas: afetividade e conflito nas relações familiares. 2008. Ribeirão Preto. Tese (Doutorado em Enfermagem Psiquiátrica) - Escola de Enfermagem de Ribeirão Preto, USP, 2008.

SOUZA, M. S.; BAPTISTA, M. N. Associações entre suporte familiar e saúde mental. Psicologia Argumento, Curitiba, v. 26, n. 54, 207-215, jul./set. 2008. 